\begin{tabular}{|l|l|l|l|l|}
\hline Cuadernos I. Geográfica & 25 & pp. 111-123 & Logroño & 1999 \\
\hline
\end{tabular}

\title{
LAS EXPLOTACIONES AURÍFERAS ROMANAS DEL RÍO DE LAS HUELGAS Y SU INFLUENCIA EN LA TRANSFORMACIÓN DEL PAISAJE ( EL EJEMPLO DE VEGUELINA DE CEPEDA, LEÓN).
}

\section{R. B. GONZÁLEZ GUTIÉRREZ}

\begin{abstract}
RESUMEN: En el presente artículo analizamos una pequeña explotación situada en el curso medio del rio de las Huelgas, afluente del rio Tuerto por la margen izquierda. El objetivo es conocer, a partir de las distintas labores realizadas, cómo se organizó y transformó un espacio específico. Dicha organización se ba conservado en cierta medida hasta la actualidad, pero se está desmantelando debido a nuevas actuaciones sobre la zona (reforestaciones) y al desconocimiento generalizado que existe sobre este tipo de explotaciones.

ABSTRACT: In this paper we are going to study a Roman Gold Mine located in the middle course of Huelgas river, Tuerto's tributary by its left side. The aim is to have a knowledge about a concrete space, which has been organized and transformed by the extractive gold works. This roman planning regional has remained until nowadays in spite of news buman activities (reafforestations) which are destroying this antique mines and because of the current-unknowledgement.
\end{abstract}

Palabras clave: Minería de oro romana, evolución del paisaje, NW de España, León .

Key words: Roman Gold Mining, Landscape Evolution, NW of Spain, Leon.

\section{Introducción}

La minería aurífera constituyó la principal actividad económica de todo el NW peninsular durante la época romana. Las técnicas empleadas en la extracción del

1. Universidad de León

C/ Valle-Inclán № 8, 24009 León 
oro implicaron un profundo conocimiento del medio físico a distintos niveles: topográficos, hidrográficos, litológicos y geomorfológicos.

En el presente artículo analizamos una pequeña explotación situada en el curso medio del río de las Huelgas, afluente del río Tuerto por la margen izquierda. El objetivo principal es conocer, a partir de las distintas labores realizadas (extracción, arrastre y lavado del mineral), cómo organizaron y transformaron un espacio específico. Dicha organización se ha conservado en cierta medida hasta mediados del presente siglo, pero se está desmantelando a partir de estas fechas debido a nuevas actuaciones sobre la zona y al desconocimiento generalizado que existe sobre este tipo de explotaciones.

Los estudios previos realizados son muy escasos, de ahí que la fuente fundamental de trabajo haya sido la fotografía aérea de $1956-57$ y el trabajo de campo. $\mathrm{El}$ "Inventario de Indicios Mineros" o la "Carta Arqueológica de la provincia de León" citan el conjunto definiendo brevemente el emplazamiento y las labores realizadas. Pérez García, en su tesis doctoral, estudia zonas próximas (valles del Omaña, Turienzo, Jerga y Duerna), pero no hace ninguna referencia a nuestra área de estudio. No obstante, las clasificaciones que realiza de las labores mineras pueden ser aplicadas también al valle del río de las Huelgas.

\section{Medio físico}

El conjunto explotado se localiza en su mayor parte en la cabecera de varios arroyos que vierten sus aguas al río de Las Huelgas (Valdebuisón, Valdevalienza, Devesa). No obstante, obtenían la captación del agua de los cauces que forman el arroyo del Madrigal, afluente del río Riofrío. La explotación removió materiales del Mioceno sup. y del Cuaternario inf. que, según el mapa geológico de la zona (RODRíguez FERNÁNDEZ, 1984), se corresponden con la serie villafranquiense que constituye la raña y con el abanico de Veguellina de Cepeda. Desde el punto de vista morfológico, estos materiales se integran en el glacis que forma el interfluvio Órbigo-Tuerto, el cual arranca de la parte meridional del cordal de Pozo Fierro, situado al Norte del área de estudio.

La explotación se localiza en un yacimiento de tipo secundario, donde el oro aparece suelto bajo la forma de láminas, de pajuelas o de polvo muy arrebolados. Posiblemente las areniscas y cuarcitas cámbricas de la serie Los Cabos, al igual que en otros yacimientos explotados en el Noroeste, constituyeron la roca madre. El mineral se encontraba en aquellos diques de cuarzo asociados a las deformaciones discontinuas (cabalgamientos y fallas tardihercínicas) que aparecían en dicha formación paleozoica. Tras su desmantelamiento y erosión, estos materiales fueron depositados durante el Oligoceno y Mioceno en forma de abanicos aluviales donde el oro aparece diseminado. No obstante, las partículas no se localizan a lo largo de toda la potencia de éstos sistemas, sino concentrado en el con- 
tacto de las dos capas mencionadas anteriormente, debido a procesos de precipitación y a concentraciones coloidales de las partículas de oro (PÉrez García et al., 1985).

Desde el punto de vista topográfico, el yacimiento se sitúa en la zona que presenta las mejores condiciones para su explotación, es decir, en los escarpes o taludes de las vertientes formados por el encajamiento progresivo de los arroyos. Éstos, a lo largo del Cuaternario han ido desmantelando la superficie pliopleistocena configurando laderas con fuertes desniveles. Estas vargas ofrecieron el emplazamiento idóneo para ubicar las minas, ya que la fuerte pendiente facilitó que el agua circulara a la suficiente velocidad como para activar su potencial erosivo y arrastrar los materiales deleznables que constituyen el glacis.

\section{Características del yacimiento explotado}

\subsection{Sistemas de labores empleados}

La zona de estudio abarca un área de $8 \mathrm{Km}^{2}$ aproximadamente. En ella se pueden distinguir dos áreas bien diferenciadas:

- Un área de explotación real que comprende las vertientes de lós afluentes del río Huelgas entre los núcleos de población de Veguellina de Cepeda y Castro de Cepeda (arroyos Valdebuisón, Valdevalienza y de la Devesa).

- Un área de abastecimiento de agua y de pequeños lavados superficiales en las cabeceras de los arroyos del río Riofrío (arroyos de las Orzonas, Palenque y de las Cervalizas).

En todo el área explotada distinguimos varios sistemas de trabajo ${ }^{1}$ (Fig.1) :

- "Sistema de corta de erosión" también denominado "sistema de ocelos" que aparece en las inmediaciones del castro. Es más, el carácter exento que presenta actualmente es debido a este tipo de labor, ya que la explotación de las márgenes del castro servía a su vez de foso de separación de la altiplanicie rañoide. El agua traída es almacenada en estanques situados al E del "ocelo" en la "montera" de la explotación. A partir de ellos se excavaron profundas zanjas-canal concéntricas que circundan el castro. El agua era enviada ladera abajo de forma concentrada a través de dos zanjas paralelas que al pie de la explotación se transformaban, tras convergir, en un canal de lavado. El estéril extraído, aunque fue de gran volumen $\left(500.000 \mathrm{~m}^{3}\right)$, no presentaba cantos de gran tamaño, de ahí la

1. Seguimos la clasificación de los sistemas de laboreo realizados por Pérez García (1977).

2. En el Inventario de Indicios Mineros (1985) se define a esta explotación como "explotación de ocelos y por canales convergentes". Indicio n⿳o. 451, perteneciente al municipio de Quintana del Castillo. 
ausencia de murias en las proximidades. La causa puede obedecer a las características de los materiales sobre los que se trabajaba. Tanto el Mioceno superior, formado por paraconglomerados con una abundante matriz arcillo-arenosa, como la raña pliocuaternaria, están formados principalmente por cantos gruesos, siendo los bloques bastante escasos.

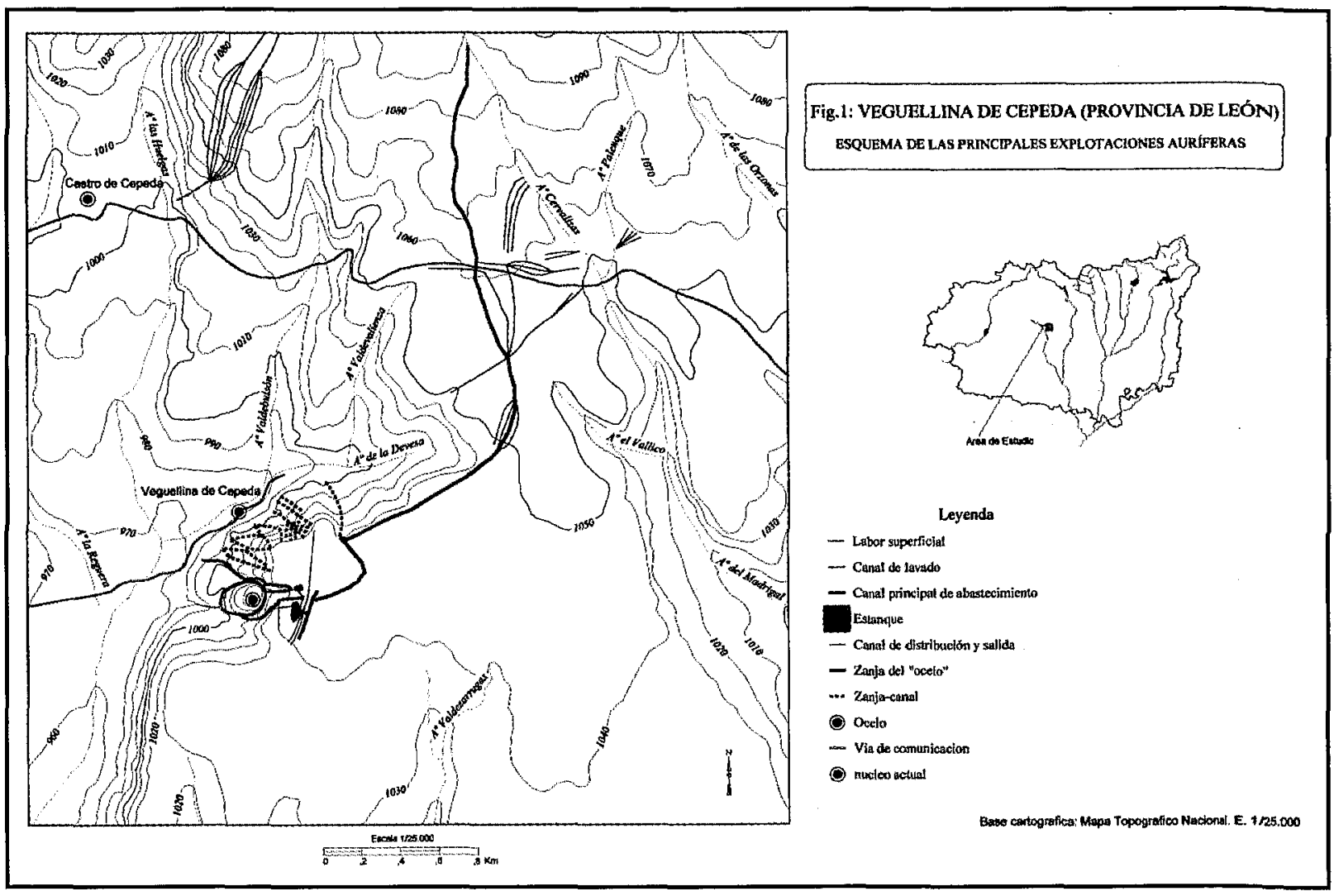

Fig. 1: Esquema de las principales explotaciones auriferas en Veguellina de Cepeda (León).

El "ocelo" formó parte de la propia explotación al estar su superficie en gran parte excavada con pozos y pequeñas zanjas de unos tres metros de profundidad, nivel donde se alcanza el contacto entre el Mioceno superior y los materiales pliocuaternarios. En un primer momento, previo al inicio de la excavación, todo el espacio formaba parte de un mismo glacis. Varias cuestiones nos lo indican: las altitudes similares existentes entre las culminaciones del castro $(1.041 \mathrm{~m}$.) y la superficie rañoide $(1.039 \mathrm{~m}$. en La Cuesta), la presencia de los mismos materiales, tanto a muro como a techo, en ambos espacios, y la propia forma de las "cárcavas" que rodean al asentamiento. Las cuatro cárcavas, dos a cada lado del "posible cerro natural" y cortadas transversalmente por otras dos, forman arcos concéntricos al montículo que difícilmente pueden ser explicables por cualquiera de los procesos morfoclimáticos naturales que generan este tipo de fenómenos. Son pues formas de origen antrópico. 
Tres estanques, ubicados en la zona más elevada del glacis, sirvieron para almacenar el agua que sería posteriormente utilizada en la explotación (Fot. $\mathrm{n}^{\mathrm{O}}$ 1). El principal es el situado más al S y se corresponde con el gran depósito de distribución o "stagnum"3 (Luzón et al., 1980). Era abastecido por el canal principal que captaba y conducía el agua procedente de la cabecera del arroyo de Cervalizas. De aquí salían diversos canales: uno llevaba el agua a las explotaciones situadas inmediatamente al $\mathrm{N}$, el otro iba a la zanja externa que rodea la margen meridional del castro, y un tercero que enlazaba con los restantes estanques. Tenía pues función doble, por un lado almacenaba el agua que llegaba, y por otro, la distribuía a los distintos sectores de la mina.

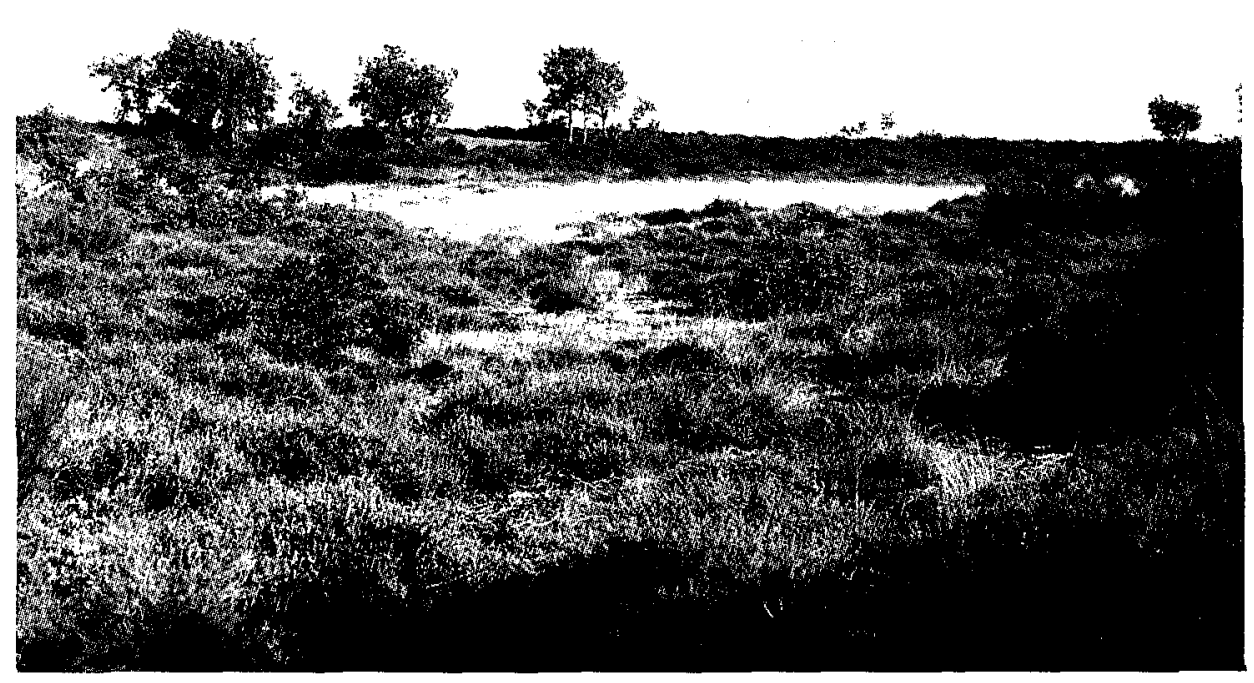

Fot. n.. 1: Estanque en la cabecera de la explotación donde se percibe el "vallum" o terraplen que se construyó para retener el agua. Actualmente está cubierto por Quercus pyrenaica $y$ de matorral Genistella tridentata. En cambio, el fondo está tapizado por pastizal.

Los otros dos estanques, situados inmediatamente al $\mathrm{N}$ y de menores dimensiones, constituían los depósitos de la explotación, los "piscinae" o "stagna" (LuZón, et al., 1980). Su función consistía en llevar el agua a través de los canales de salida o "emissaria" para ser directamente arrojada en las zanjas-canal. El

3. Los conceptos latinos que se van a utilizar (stagnum, stagna, piscinaes, corrugi, emissaria, agogae, etc) se basan en la terminología usada por Plinio el Viejo, uno de los autores que describieron los tipos de las labores realizadas en los distintos yacimientos. 
más pequeño está abierto hacia una de las zanjas transversales, que a su vez comunica con las zanjas concéntricas meridionales. El otro, situado justo al $\mathrm{N}$, comunica con las zanjas que rodean al castro por su margen septentrional.

El "ocelo" aparece circundado por dos profundas zanjas-canal. Las más internas, son las que lo separan completamente de la raña. Presentan un desnivel de unos 20 metros y están unidas en su tramo final por el "agogae" o canal de lavado. Las externas sólo rodean el sector oriental del castro. La más meridional converge con la interna para formar una sola zanja. La septentrional tiene unas dimensiones menores y, además, se bifurca a media ladera hacia el NW. Este ramal se transforma en una zanja rectilínea paralela a la pendiente máxima enlazando con otras zanjas que se sitúan más al N. Las cuatro hendiduras están cortadas transversalmente en su extremo más oriental por otras dos zanjas. Están unidas a los estanques de la explotación, bien directamente a través de la abertura del "stagnum" más pequeño, o bien a través de un pequeño canal de salida.

- "Sistema de grandes zanjas". Son las labores localizadas inmediatamente al $\mathrm{N}$ de la anterior en la ladera a cuyos pies se asienta el actual pueblo de Veguellina y que vierte sus aguas al arroyo de la Devesa. El agua era conducida hasta la cabecera de la mina por canales de salida o "emissaria" que provenían del estanque principal y por los canales generales de captura y conducción procedentes del NE. Las zanjas presentan unas características específicas que las diferencian de las del sistema anterior. Generalmente son profundas incisiones rectilineas que siguen la línea de máxima pendiente. Algunas, en la parte culminante de la ladera, se bifurcan en varios canales dando el aspecto de un pequeño sistema en arados; otras son una sola zanja-canal que recorre toda la ladera. El agua era arrojada directamënte de forma concentrada. El volumen de material extraído es mucho menor que él de la excavación anterior. (1.000 $\mathrm{m}^{3}$ según el Inventario de Indicios Mineros).

Su aspecto actual, profundas cárcavas lineales (Fot. no 2), no puede ser confundido con las formas naturales relacionadas con la arroyada concentrada por varias razones. La primera es que están situadas en el borde del glacis, borde que está suavemente inclinado hacia el E y no hacia el $\mathrm{O}$, donde se localizan las cárcavas. Esto indica que el escurrimiento general no se dirige hacia el arroyo de la Devesa, sino hacia el del Madrigal. La segunda es que no tienen una cuenca vertiente, salvo los tres estanques artificiales de la cabecera, que capte el agua y la dirija por el talud hasta el fondo del valle.

- Sistemas superficiales de lavado basados en "canales aislados" y en "canales en forma de cola de caballo" (Pérez GARCíA, 1977). Estas labores son características de zonas donde los depósitos explotados presentan espesores poco potentes: terrazas, rañas, suelos, etc. De ahí que sean los sistemas más rápidos y menos trabajosos. Son pequeños lavados de prospecciones muy superficiales (algunos no 
alcanzan el metro de profundidad) cuya finalidad era averiguar las concentraciones de oro en distintos lugares ${ }^{4}$. Tras conocer la concentración de oro, se procedía a su explotación si ésta era suficientemente ricas. Si no lo era, se abandona$\mathrm{ba}$, quedando leves incisiones sobre el terreno, siempre y cuando éstas se hayan conservado a lo largo del tiempo.

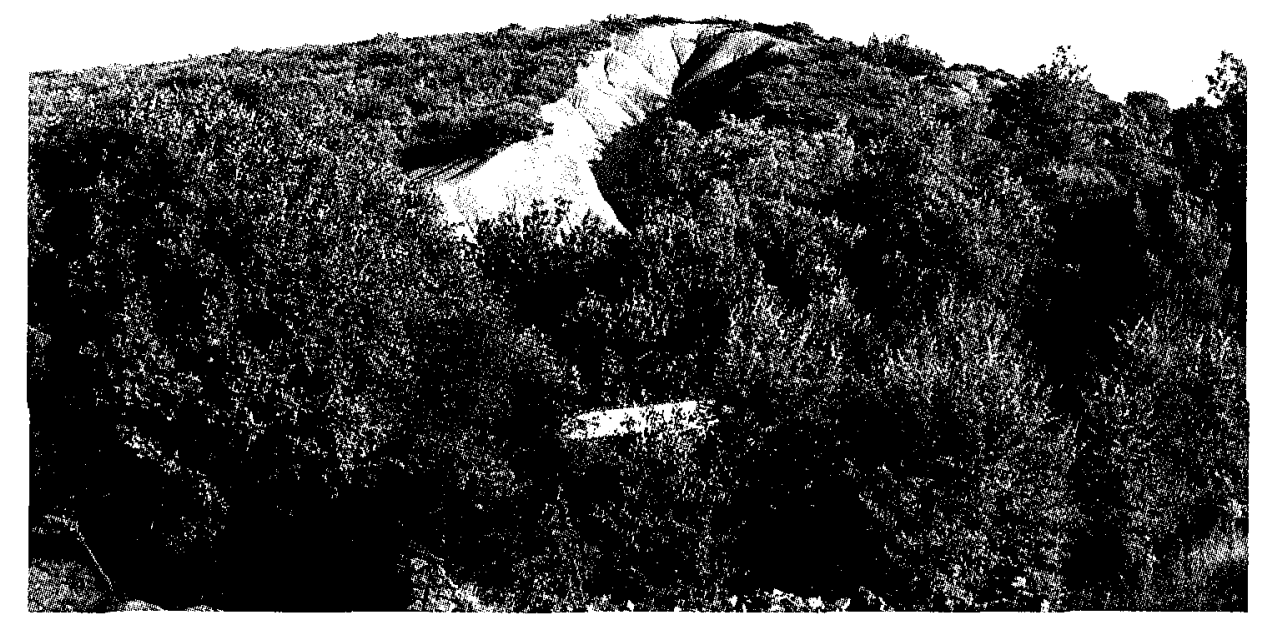

Fot. n. 2: Zanja-canal vista desde el pueblo de Veguellina de Cepeda. Los arbustos de rebollo ban colonizado la mayor parte de la explotación salvo las antiguas trincheras donde la pendiente es mucho más fuerte.

Por esta razón son las labores más frecuentes en el área de estudio. Se localizan no sólo en las zonas explotadas por otros sistemas, sino también en los lugares donde se captaba el agua o incluso en el mismo recorrido de los canales que abastecían a las minas, como por ejemplo en el interfluvio de los arroyos de la Devesa y el Vallico.

Ejemplo claro de este sistema lo encontramos en las proximidades de Castro de Cepeda, al ENE. Las catas constituyen un sistema de canales en forma de cola de caballo localizados en la vertiente oriental del río de las Huelgas. El agua, cap-

4. Para los abanicos pleistocenos Pérez García (1977) establece una ley que varía de las zonas más próximas a las áreas madre, donde la concentración de oro era mayor (60$100 \mathrm{mg} / \mathrm{m}^{3}$ ), a las distales con leyes que oscilaban entre $10-20 \mathrm{mg} / \mathrm{m}^{3}$. La riqueza del mineral varía también del techo al muro del sedimento, siendo las capas superiores las menos ricas $\left(10-15 \mathrm{mg} / \mathrm{m}^{3}\right)$.

5. Según Herail et al., (1989) los romanos no explotaban aquellos yacimientos secundarios que tenían una ley inferior a $15-20 \mathrm{gm} / \mathrm{m}^{3}$. 
tada en la cabecera del arroyo Valdebuisón, era conducida siguiendo la pendiente del glacis hasta la parte culminante del escarpe. A partir de aquí, y aprovechando el fuerte desnivel, los canales se bifurcan en dos haces de seis o siete canalillos, convergiendo de nuevo en el fondo del valle en el canal de lavado.

Otros ejemplos los tenemos en la proximidades del "ocelo" de Veguellina (al $\mathrm{E}$ de los estanques), en la margen derecha del arroyo de las Cervalizas, en el paraje denominado Las Quemadas y en las proximidades de la confluencia del arroyo de las Cevalizas y del Palenque. En estas zonas de muy poca pendiente los canales de abastecimiento son excavados en profundidad o bien se bifurcan en varios ramales para realizar pequeños "demuestres".

\subsection{Sistema bidráulico.}

La necesidad de agua para poder realizar las distintas labores de prospección y extracción del mineral es fundamental en la minería aurífera romana. Cada explotación contiene numerosos canales con funciones distintas, aunque todos ellos tiene una característica común, y es que han sido trazados siguiendo una pendiente mínima que oscila entre el $0,5 \%$ y $1 \%$. En nuestra zona se distinguen varios tipos (Fig. 1):

- Canales principales de abastecimiento. Recogían el agua de distintos cursos fluviales conduciéndola hasta las proximidades de las minas. La captura fundamental se realizaba en la cabecera del arroyo de Cervalizas a unos $1.090 \mathrm{~m}$ de altitud. El canal, con una dirección N-S, era conducido a la explotación principal por la parte culminante del glacis siguiendo la pendiente. Posiblemente existieron otras captaciones en los arroyos situados más hacia al E, (Palenque, Orzonas e incluso, Valcabao), pero la repoblación realizada en los años cincuenta ha destruido en gran parte esta infraestructura. En la fotografía aérea del 1955-56 podemos observar pequeños tramos de posibles carriles que se pierden al ser desmantelados por las fajas construidas para repoblar los interfluvios de estos arroyos.

- Canales de distribución. De los corrugi o canales principales anteriores partían pequeños canales que distribuían el agua hasta al pie de las explotaciones. A veces, captaban el agua de arroyos próximos (ej.: Palenque) para realizar excavaciones superficiales. En la zona tenemos numerosos canales de este tipo. Del canal principal salían varios ramales siendo uno de los principales el localizado a la altura de la intersección de dicho canal con la carretera que va de Morriondo a Castro de Cepeda. De aquí, se distribuían canales hacia la confluencia del arroyo Cervalizas con el Palenque y hacia la cabecera del Valdevalienza. Otro cruce de distribución estaba situado más al S, en el paraje de Las Quemadas. De aquí, partían hacia la margen derecha de la cabecera del arroyo de la Devesa y hacia la explotación principal donde desembocan en los estanques de distribución o "stagna". 
- Canales de salida o "emissaria". Son los canales que arrojaban el agua desde las "piscinae" a la cabecera de la propia mina. Algunos se transformaron posteriormente en zanjas-canal, como las transversales que comunican los estanques con las zanjas de explotación del "ocelo" (Luzón et al., 1980).

- Canales de lavado o "agogae". Se localizan en las partes más bajas de las cortas y eran utilizados para el lavar el mineral y separarlo del resto del aluvión. Pueden ser comparables a los canales de madera que se utilizaron con el mismo fin en los yacimientos auríferos de Castrillo de la Valduerna en los años setenta del presente siglo o de California (SÁnCHEZ-PALENCIA, 1983). En su interior tenían ramas de plantas resinosas tales como brezos o tojos," las ulices", (LuENGo UGIDOs, 1992) sujetas por piedras que servían para retener las partículas de oro. Los hemos localizado al pie del ocelo de Veguellina en la unión de las zanjas concéntricas y en la parte final de algunas de las explotaciones superficiales cuando éstas alcanzaban cierta magnitud (labores superficiales en forma de cola de caballo en las proximidades de Castro de Cepeda).

Relacionada con la red hidráulica debemos tener en cuenta dos aspectos que aparecen en las fotografias aéreas. El primero es la posterior transformación de estos canales, en carriles o caminos (GARCía DE Celis, et al., 1996). Tras el abandono de las minas, estos canales eran fácilmente reutilizables para caminos dado que eran espacios ya desbrozados y además, presentaban una pendiente uniforme a lo largo de la mayor parte de su trazado. Este cambio de uso desarticuló en cierta medida la infraestructura que se observa a través de la foto aérea, ya que en ocasiones aparecen tramos que no tienen, según nuestro parecer, una explicación lógica cuando se realiza la fotointerpretación.

El segundo aspecto hace referencia al carácter dinámico de las explotaciones. A medida que remontaban los cursos de agua, para realizar nuevas excavaciones, era necesario trazar nuevos canales de captación y distribución. Y a su vez, eran abandonados aquéllos que ya no se utilizaban cuando la explotación cesaba o se desplazaba de nivel. Esto dificulta también la interpretación actual ya que muchas de las marcas que aún se conservan se cruzan entre sí o simplemente desaparecen.

\subsection{Sistema de explotación}

Teniendo en cuenta las distintas labores realizadas y el sistema hidráulico de abastecimiento de agua se puede establecer un esquema del trabajo realizado en el entorno de Castro y Veguellina de Cepeda.

La primera labor que se realizó fue el trazado de la red hidraúlica de "corrugi", "piscinae" y "stagna" con el fin de conducir el agua necesaria para la extracción, arrastre y lavado del mineral. Su trazado se hacía remontando el terreno 
desde el yacimiento principal a explotar hasta los arroyos cabecera desde donde se captaba el agua.

Una vez construida la red se procedía a la extracción del mineral. En una primera fase se realizaron lavados superficiales con el fin de prospectar el yacimiento. Es cuando se construyen los canales en forma de "cola de caballo" y se profundiza en algunos de ellos, transformándose en pequeños canales-zanjas aislados. Localizadas las concentraciones más importantes se procede a la extracción del oro con sistemas más complejos. La raña plio-pleistocena, dada su poca profundidad, fue explotada mediante dos sistemas: cortas de erosión y grandes zanjas-canal. Estas técnicas son típicas de yacimientos extensivos donde el oro aparece diseminado y su ley no es muy elevada. Las zanjas aprovecharon los desniveles existentes entre la superficie culminante de la raña y el fondo del valle (unos $40 \mathrm{~m}$ ), produciendo abarrancamientos, similares a los originados por las arroyadas naturales. En este momento es cuando se realizan las zanjas que rodean el castro o las ubicadas al $\mathrm{N}$ del emplazamiento (Fig. 2).

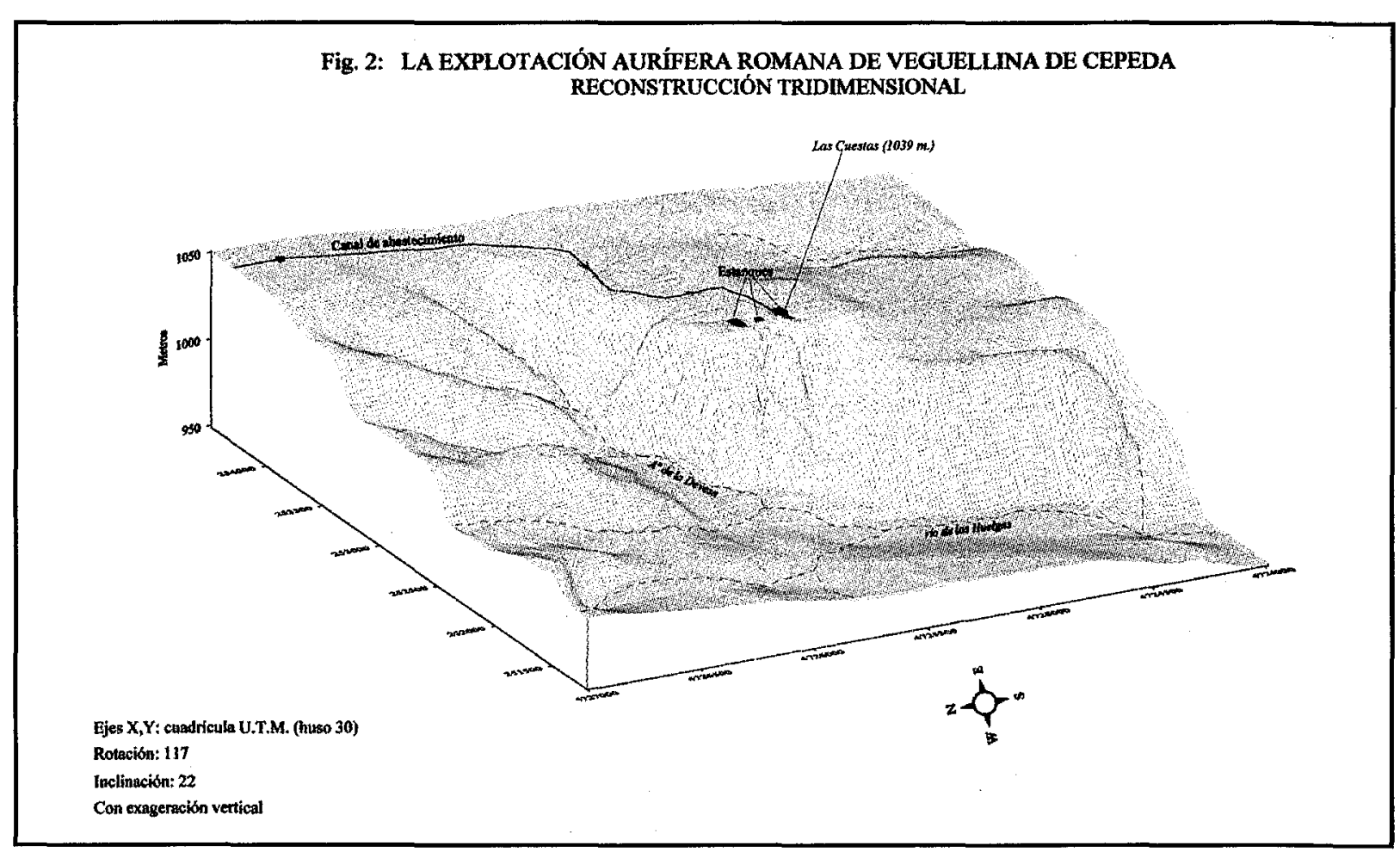

Fig. 2: La explotación aurifera romana de Veguellina de Cepeda.

El siguiente paso es el lavado del mineral separándolo del resto de la ganga. Este lavado se efectúa encauzando todo el material arrastrado por el agua hasta las "agogae" donde el oro se depositaba gracias a los tojos y piedras que servían de obstáculo. Una vez que cierta cantidad de aluvión había pasado por el canal, el fondo era limpiado y las "ulices" se quemaban. Las cenizas de éstas, junto con 
el concentrado recogido del canal, eran bateados para obtener ya finalmente el mineral (SÁNCHEZ-PALENCIA, 1983).

\section{Transformación del paisaje y su conservación actual}

No cabe duda que todo el conjunto de labores realizadas modificaron profundamente el paisaje aunque de forma puntual. Posiblemente fueron los primeros en desbrozar masivamente las formaciones vegetales existentes. Al intentar imitar los procesos naturales de la arroyada concentrada eliminaron completamente la cubierta edáfica y provocaron la formación de un profundo sistema de acarcavamientos, que es el que actualmente se reconoce en el campo con más facilidad. Realizaron trasvases de agua de unas cuencas ${ }^{6}$ a otras modificando los caudales de los ríos y los mismos cursos fluviales. Un ejemplo claro lo tenemos en las Médulas de Las Omañas o Traviesas, donde los estériles o murias de la explotación desviaron el curso del río Omaña hacia su margen izquierda a la altura de la localidad del mismo nombre 7 . En nuestro área el trasvase se realizó de la subcuenca del río Riofrío, tributario del Órbigo, a la del río de las Huelgas, afluente del Tuerto.

Esta transformación tan profunda, "que imita a formas debidas a procesos naturales", ha hecho que actualmente muchos de los antiguos laboreos sean confundidos con dichas formas. Así, se interpretan las zanjas-canal como formas de arroyada concentrada o los estériles abandonados ("murias") al pie de las minas con conos de deyección, o depósitos aluviales cuaternarios (GARCía DE CELIS, et al., 1996; LUENGo, UGIDOS et al., 1995).

La conservación actual de estas explotaciones depende de dos factores. Por un lado, del grado de trasformación del paisaje cuando la mina estaba activa y, por otro, de la reutilización que se ha hecho de este espacio una vez que cesaba el laboreo a lo largo de los siglos.

Los cambios más importantes se realizaron en las áreas donde se extraía el mineral. El desmantelamiento de los suelos y la formación de profundas cárcavas con unos desniveles elevados han impedido que estos espacios fueran utilizados para los usos agrícolas tradicionales. Son los espacios mejor conservados produciéndose además una regeneración de las posibles formaciones vegetales autóctonas, es decir, del Quercus pyrenaica. Donde la pendiente lo permite, los rebollos han sido los principales colonizadores del antiguo paisaje de "trincheras $y$ escombros" (zanjas próximas al "ocelo").

6. En ocasiones los trasvases los realizaron entre las cuencas principales de Miño y del Duero.

7. Otro ejemplo lo tenemos en Montefurado (Lugo), donde desviaron el curso del río Sil a través de un túnel horadado en la roca, con el fin de explotar los aluviones de un meandro encajado. 
En cambio, aquellas zonas que se transformaron menos, las utilizadas pa ra la creación de toda la infraestructura hidráulica, han sido aprovechadas por el sistema agropastoril tradicional. Un ejemplo es la presencia de caminos de acceso a campos de cultivo con el nombre de carriles. En el paraje de Las Quemadas, se observa a través de la fotografía aérea como varios de los caminos siguen los antiguos canales de distribución ya que a veces en las márgenes de los mismos aparecen pequeñas muescas o incisiones rectilineas que van a parar a dichas vías.

Pero, a pesar de este uso tradicional del espacio, se han conservado gran parte de los canales y estanques ya que las labores agrícolas no modificaban excesivamente la topografía del terreno. No ocurre lo mismo con las actuaciones que se están realizando actualmente. Las repoblaciones forestales y las concentraciones parcelarias borran todo huella o vestigio de las antiguas labores (GARCÍA DE CELIS et.al., 1996). Las plantaciones de pinos realizadas en los años cincuenta y sesenta entre los arroyos de Las Cervalizas y Valcabao eliminaron la mayor parte de los canales de captura y conducción que abastecían a toda la zona de estudio. Lo único que permanecen son pequeños canales-zanja en los bordes y algún topónimo relacionado con aquella actividad extractiva.

\section{Referencias bibliográficas}

Domergue, C., 1970. Introduction à l'étude des mines d'or du Nord-Ouest de la Péninsule Ibérique dans l'antiquité. Legio VII Gemina. cátedra de San Isidoro. Excma Diputación Provincial de León., 253-286.

García de Celis, A., González, R.B., Luengo, M.A., Redondo, J.Mª ., 1996. Un ejemplo de explotación romana de yacimiento primario: la mina del río de la Sierra (León). Estudios Humanísticos, 17: 11-29.

Herail, G. y Pérez García, L.C., 1989. Intérêt archéologique d’un étude géomorpho-gitologique: les gisements d'or alluvial du Nord-ouest de 1'Espagne. Minería y Metalurgia en las antiguas civilizaciones mediterráneas y europeas, vol II: 21-33. Ministerio de Cultura. Madrid.

JuntA de CASTILla y LEÓN, 1986. Inventario de indicios mineros, Consejería de Industria, Energía y Trabajo. Valladolid.

LUENGO, M.A. , 1992. Estudio del relieve del sector oriental de los Montes de León, 3 vol, Universidad de Salamanca, (Tesis Doc. inedt.).

Luengo, M.A. García de Celis, A. y Redondo, J.Maa., 1993. Depósitos cuaternarios y minería romana en las montañas del NW. de la Península Ibérica. $3^{a}$ Reunión del Cuaternario Ibérico. Actas. 141-148. G.T.P.O.-A.E.Q.U.A. Coimbra.

LuENGo, M.A. Y REDONDO, J.Mํ. ., 1995. Modelado de vertientes y minería antigua en el NW peninsular. Simposio Internacional Paleoambiente Cuaternario en la Peninsula Ibérica. Santiago de Compostela. 
LuZon, J.Mํ. y SÁnCheZ-PALENCiA, F.J., 1980. Excavaciones arqueológicas en España. El Caurel, 155 pp. Ministerio de Cultura. Madrid.

PÉREZ GARCía, L.C., 1977. Los sedimentos auríferos del NO. de la cuenca del Duero (provincia de León, España) y su prospección. Tesis Doc. (inedt). Liniversidad de Oviedo.

Pérez García, L.C. y Sánchez-Palencia, F.J., 1985. Yacimientos auríferos ibéricos en la antigüedad. Investigación y Ciencia, 104: 64-75. Barcelona.

Redondo, J.M.a., Luengo, M.A., y GarCía De Celis, A., 1991. Estudio espacial de la actividad minera en la cuenca del río Omaña. Evaluación del impacto ambiental del embalse de Omaña. C.H.D.-Univ. de León.

Rodríguez Fernández, L.R., 1984. Mapa Geológico de España, 160, Benavides. Ministerio de Industria y Energía. Madrid.

SÁnCHEZ-PALFNCIA, F.J., 1980, Prospecciones en las explotaciones auríferas del noroeste de España (cuencas de los ríos Eria y Cabrera y Sierra del Teleno), $N A H, 8: 215-249$.

SÁnChliz-PaIEnCIA, F.J., 1983. Explotaciones auríferas en el Conventus Asturun. Indigenas y romanización en el Conventus Asturum, 69-87. Ministerio de Cultura-Universidad de Oviedo. Madrid.

V.V. A.A., 1987. Carta arqueológica de la provincia de León, (inédito). Universidad de León. 